\title{
Education and Intergenerational Social Mobility in the US and four European Countries
}

Richard Breen, Nuffield College and Department of Sociology, University of Oxford

\section{Abstract}

I draw on the findings of a recently completed comparative research project to address the question: how did intergenerational social mobility change over cohorts of men and women born in the first two-thirds of the $20^{\text {th }}$ century, and what role, if any, did education play in this? The countries studied are the US, France, Germany, the Netherlands, and Sweden. Notwithstanding the differences between them, by and large they present the same picture. Rates of upward mobility increased among cohorts born in the second quarter of the century and then declined among those born later. Among earlier born cohorts, social fluidity increased (that is, the association between the class a person was born into and the class he or she came to occupy as an adult declined) and then remained unchanged for those born after mid-century. The association between class origins and educational attainment followed much the same trend as social fluidity. This suggests that growing equalization in education may have contributed to the increase in social fluidity. In our analyses we find that this is so, but educational expansion also led to greater fluidity in some countries. There is also a strong link between upward mobility and social fluidity. Upward mobility was mostly driven by the expansion of higher-level white-collar jobs, especially in the 30 years after the end of the Second World War. This facilitated social fluidity because people from working class and farming origins could move into the service or salariat classes without reducing the rate at which children born into those classes could remain there. Educational expansion, educational equalization, and rapid structural change in the economies of the US and Europe all contributed to greater social fluidity among people born in the second quarter of the $20^{\text {th }}$ century. For people born after mid-century rates of downward mobility have increased: however, despite the lack of further 
educational equalization and less pronounced structural change, social fluidity has remained unchanged. 


\section{Education and Intergenerational Social Mobility in the US and four European Countries}

\section{Introduction}

This chapter documents change over the 20th century in intergenerational social class mobility, both absolute and relative, in the US and four core EU countries (Germany, France, Sweden and the Netherlands), with a particular focus on the role played by education in the evolution of mobility. The results I present come from a bigger study that covers eight European countries and the USA and involves a large number of collaborators. ${ }^{1}$ The origins of this project lie in two papers (Breen et al 2009, 2010) in which we reported that, in eight European countries, the association between class origins and educational attainment weakened across cohorts born throughout the first two-thirds of the century. In other words, the education people attained became less closely linked to their social class background. This may seem an unsurprising result but it went against the wisdom that had prevailed among sociologists since the early 1990s. Following Shavit and Blossfeld (1993) it had been widely accepted that, despite dramatic educational expansion during the twentieth century, of the thirteen countries studied in their project, all but two, Sweden and the Netherlands,

exhibit stability of socio-economic inequalities of educational opportunities. Thus, whereas the proportions of all social classes attending all educational levels have increased, the relative advantage associated with privileged origins persists in all but two of the thirteen societies (Shavit and Blossfeld 1993: 22).

Following from these papers, it seemed natural to investigate whether the weakening of the link between origins and education that we had found was associated with a weakening link between origins and class destinations - in other words, with great "social fluidity" in intergenerational class mobility. Our interest in the role of education for mobility also spoke to some specific political

${ }^{1}$ Education and Intergenerational Social Mobility in Europe and the United States, edited by Richard Breen and Walter Müller, forthcoming from Stanford University Press. 
and policy concerns. In the US and UK, though less so in continental European countries, social mobility is a matter of some public concern. These concerns were summarised by US President Barack Obama, speaking in 2013:

“The problem is that alongside increased inequality, we've seen diminished levels of upward mobility in recent years. A child born in the top 20 percent has about a 2-in-3 chance of staying at or near the top. A child born into the bottom 20 percent has a less than 1-in-20 shot at making it to the top. He's 10 times likelier to stay where he is. In fact, statistics show not only that our levels of income inequality rank near countries like Jamaica and Argentina, but that it is harder today for a child born here in America to improve her station in life than it is for children in most of our wealthy allies -- countries like Canada or Germany or France. They have greater mobility than we do, not less."

Education is the mechanism most often suggested as the solution to these mobility problems, but contemporary research is far from reassuring that education is up to the job. This is because, although there is no question that education is the single strongest predictor of the class a person will come to occupy, studies about the role of educational change for changing social mobility have come to conflicting conclusions. While many authors report evidence that changes in education affect intergenerational mobility (for example, Blanden, Gregg and Machin 2005; Causa and Johansson 2010; Mayer and Lopoo 2008) others are sceptical (Goldthorpe 2007). Research on the impact of the raising of the school leaving age in England and Wales in 1972 showed that, although it led to an increase in the average number of years of schooling completed, it had no discernible effect on intergenerational mobility (Buscha and Sturgis 2015). A US study (Rauscher 2016), focusing on the introduction of compulsory schooling laws in the US in the $19^{\text {th }}$ century, also failed to find a positive impact on mobility. On the other hand, Betthäuser (2017) found that increasing the school leaving age in Germany promoted greater intergenerational mobility. Our hope was that by examining what happened in the past might we might come to a better understanding of the link, if any, between educational change and change in intergenerational mobility. In the process, however, our project expanded 
into a broader description of how intergenerational mobility evolved over the $20^{\text {th }}$ century and the striking similarities among countries in this (as well as the differences). In this paper I will summarize those findings and explain what, if anything, history has to teach us about the role of education in social mobility.

\section{How Sociologists study Social Mobility}

Economists approach the study of intergenerational mobility by looking at the relationship between a person's income or earnings and those of her or, more usually, his parents (usually the father). Regressing the logarithm of the former on the latter yields an estimate of the intergenerational income elasticity, which captures the strength of the relationship between the incomes of people and their parents and is thus inversely related to the extent of intergenerational income mobility. Among developed countries this elasticity has been found to range between about 0.4 or higher in the US and about 0.2 in the Scandinavian countries.

For sociologists the basic datum for the study of intergenerational social mobility is a table, cross-classifying a person's own class with that of his or her parents (in practice this is usually the respondent's father) when that person was a teenager. Social classes are groups of occupations put together because they are thought to be similar in important ways. In all cases (except in those countries that have comprehensive register data) the information comes from surveys and data about parental occupation and class usually come from the respondent. Nevertheless, such reports seem to be highly reliable (Breen and Jonsson 1997). As a consequence we can look at change in intergenerational class mobility over long periods of historical time in a way that would not be possible for intergenerational income mobility. We can rely on respondents' reports of their class origins to a much greater extent than we could rely on respondents' reports of their parents' income.

Sociologists use two kinds of measures of intergenerational mobility - absolute and relative. Absolute mobility refers to the observed patterns of movement between origins and destinations. The simplest measure of absolute mobility is 
the proportion of people who are in a destination that differs from their origin: this is the overall mobility rate. Within absolute mobility we can separate upward from downward moves, and we can ask whether these are more common among people from one class origin compared to another. And, rather than focusing on where people from particular origins move to, we might examine where the people in a class destination came from, and ask how far a certain class destination is recruited from particular class origins.

Relative mobility, or social fluidity, deals with the strength of the relationship between origins and destinations. Measures of relative mobility capture the degree to which a person's destination depends on their origin. In the absence of changes in the class structure - that is, in the sizes of the different classes - the relative mobility chances of people from one class origin can improve only to the extent that the chances of people from one or more classes worsen. Complete social fluidity, also known as perfect mobility, would hold if destinations were independent of origins. The association between origins and destinations is captured by odds ratios or their logarithm. Large odds ratios mean low social fluidity and origins that are strongly associated with destinations.

To compare social fluidity across tables representing countries or birth cohorts or other groups, sociologists often use a single number per table. One statistic of this kind is the unidiff coefficient, $\varphi$ which seeks to capture the relative strength of the origin - destination association across a set of tables. We usually set $\varphi=1$ for one table, and thus $\varphi_{k}<1$ means greater social fluidity in table $k$ than in the reference table (a weaker association between class origins and class destinations) and, conversely, $\varphi_{k}>1$ means less social fluidity in table $k$ than in the reference table. The unidiff models rests on the assumption that the odds ratios in all the tables have the same pattern, and differ only by being raised or lowered by the unidiff coefficient. Figure 1 is taken from Social Mobility in Europe (Breen 2004) and shows the unidiff estimates for eight European countries in each of three decades -- the 1970s, 1980s and 1990s. The unidiff values for each country are relative to that for England and Wales in the 1980s (shown in the middle of the figure). Two things stand out. First, the association 
between origins and destinations weakened, particularly between the 1970s and 1980s. And, second, there are two clear groups of countries: the less socially fluid Germany, France and Ireland, where origins have a stronger association with destinations, and the more fluid countries, Sweden, Poland, Hungary and the Netherlands.

[Figure 1 here]

\section{Cohort Change}

The analyses of Social Mobility in Europe adopted a period perspective, comparing mobility in the 1970s, 1980s and 1990s. But our subsequent work, and that of others (notably Müller and Pollak 2004) led us to conclude that "most changes in fluidity that we observe in stable democratic societies will arise from processes of cohort replacement" (Breen and Jonsson 2007: 1782); in other words, fluidity will increase when less fluid older cohorts exit the labour market and are replaced by younger, more fluid cohorts. Accordingly, our current research into trends in educational change and social mobility has used a cohort perspective, comparing people born at different times.

In this paper I report the results of studies of change in the $20^{\text {th }}$ century in the United States and in Germany, Sweden, France and the Netherlands. Sweden is the classic example of a social democratic state, with extensive social welfare and regulated labour markets. The US, on the other hand, is the archetypal liberal regime with limited social welfare provisions (compared with many European countries) and relatively lightly regulated markets. The other countries in our sample are usually classified together as continental welfare regimes, which are “conservative and strongly 'corporatist'... [and in which] rights ... were attached to class and status" (Esping Andersen 1990: 27, parentheses added). But within this grouping there are important differences. For example, Germany and the Netherlands, but not France, are part of what Hall and Soskice (2003) call 'coordinated market economies'. Of particular importance, from our perspective, is that, in both countries, vocational training is a significant part of the educational system. In Germany this takes the form of the 'dual system' of 
vocational training in which young people in vocational education divide their week between school (Berufsschule) and working for a company as an apprentice. In the Netherlands vocational training is largely school based. In both cases, however, this vocational emphasis helps to ensure a close match between the skills acquired in education and those required by employers.

In terms of education and how it changed over the $20^{\text {th }}$ century, we can divide our countries in different ways. For example, while the US and the Netherlands expanded academic tertiary education (albeit at different times during the century), this strategy was not pursued to anything like the same extent in Germany or Sweden where such tertiary expansion as has occurred has to a large extent been at the technical or vocational level - Fachhochschulen in Germany and Tekniska Högskolan in Sweden.

The reason for carrying out analyses involving five countries, rather than focusing on a single one, must be found in what we can learn from a comparative perspective. The comparisons I draw are not between countries in their levels of mobility and fluidity but in their trends. In other words, did changes in social fluidity during the $20^{\text {th }}$ century follow similar or different patterns, did they occur at much the same time, and, crucially, were changes in education associated with them?

To answer these questions we need to ensure that the class classifications used in each country are, if not exactly the same, then sufficiently similar. In all countries, we have employed the principles of the widely used Erikson Goldthorpe class schema (Erikson and Goldthorpe 1992; Goldthorpe 2000; Breen 2005) to allocate respondents and their parents to classes. In all five countries the same class classification is used:

Class I - Higher Professional and Managers

Class II - Lower Professional and Managers

Class IIIa - Higher Routine Non-Manual

Class IVab- Self Employed 
Class IVc - Farmers

Class V+VI - Skilled Manual

Class IIIb+VII - Lower Routine Non-Manual and Unskilled Manual.

We assign people to their highest educational level using the CASMIN educational schema (Müller and Haun 1994) usually with 5 categories, distinguishing Compulsory only, Lower Secondary, Upper Secondary, Lower Tertiary (mostly shorter Vocational courses), and Upper (or Academic) Tertiary.

We want to examine change in education and mobility over the $20^{\text {th }}$ century and we have done this by drawing on surveys from each country fielded between about 1970 and 2010. We focus on men and women in the labour force aged between 35 and 70 (there is some variation between countries in the upper and lower limit) and, in most cases, we define six birth cohorts: 1924 and earlier; 1925-34; 1935-44; 1945-54; 1955-64; 1965 and later. We have some cases born as far back as 1906 but generally we have rather few born before about 1916, and we have no observations of people born after 1974. The cohorts for the US are defined slightly differently: 1908-21, 1922-33, 1934-45, 1946-57, 1958-69, 1970-79. However, we use the same labels for the US cohorts in the figures in this chapter.

Class structural change and social fluidity

The 20th century was a time of great change in the class structure of society. Societies that were rooted in the land, where most people worked in agriculture, gave way to urban societies, initially based around industry and manufacturing and, latterly, service occupations. At the same time, gender differences in labour market participation declined and occupational or class segregation by gender also diminished. In our data we see these changes in the upgrading of the class destination distributions of men and women, shown in Figures $2 \mathrm{a}$ and $2 \mathrm{~b}$ as the share of each cohort in the service class (classes I and II) and in the unskilled manual class. The patterns are similar for men and women, except that, for the former, the increase in the service class tails off in the later born cohorts but, among women, the expansion of the service class continued throughout the 
century. The growth at the top of the class structure was mirrored by decline in all other classes, but particularly in the unskilled classes and the classes of farmers and farm labourers. The decline in unskilled work was much more dramatic for women than men. At the start of the century, women were much more heavily concentrated here; by its end women were still overrepresented but to a much lesser degree.

[Figures $2 \mathrm{a}$ and $2 \mathrm{~b}$ here]

These changes in the class structure went together with changes in upward and downward mobility rates ${ }^{2}$ as Figures $3 a$ and $3 b$ show. Among men there is a pattern of increasing upward mobility and diminishing downward mobility among the earlier born cohorts, followed by declining upward mobility and increasing downward mobility in the later born cohorts. Among women, rates of upward mobility increased then flattened out, rather than declined, in the later born cohorts and, similarly, downward mobility declined then remained constant, rather than increasing. In all countries, the growth in upward mobility among men was almost entirely due to the growth in the service class (I and II). Among women, however, the growth in class III (higher routine non-manual employment) was also important.

[Figure 3 here]

The trends in social fluidity are very similar to those for upward mobility. These can be seen in in Figure 4, which plots the country-specific unidiff parameters for the origin - destination association, with each country's initial value set to one in the oldest cohort. For men there is a pronounced weakening of the origindestination association in the cohorts born up to 1945-54 and then rather little

2 Downward mobility is defined as movement from class I to any other class; from class II to any class except I or II; and, for all other classes except VII/IIIb, movement to class VII/IIIb. Upward mobility is defined as movement from class II to class I; from class VII/IIIb to any other class except VII/IIIb; and, for all remaining classes except class I, movement into classes I or II. 
change afterwards. For women, however, the trend towards greater fluidity persisted until the 1955-64 and, in France it continued to our youngest cohort. ${ }^{3}$ Social fluidity among men in the US increased greatly up to the 1945-54 birth cohort, then remained constant, similar to the prevailing European pattern. But among women, after a small increase between the oldest and second-oldest cohorts, there was no further change in social fluidity.

[Figure 4 here]

\section{Trends in Education}

The upgrading of education during the $20^{\text {th }}$ century is well known and we see, in Figures $5 \mathrm{a}$ and $5 \mathrm{~b}$, that it is captured in our data. The figures show the steady decline in the proportion of people with only elementary education and the growth in the share with a Tertiary qualification. Countries in which agriculture accounted for a large share of the population at the start of the $20^{\text {th }}$ century, such as France and Sweden, had very large shares of people with elementary education in the oldest cohort: they have shown the greatest change from a low educated to a high educated population. In Germany and the Netherlands, by contrast, the share of people in the earlier born cohorts with elementary education was relatively low. This arises from their long tradition of vocational education, obtained by large proportions of young people either in dual system institutions (Germany) or in special sections of the school system the Netherlands).

In the oldest cohort, women were more likely than men to possess only elementary qualifications, but, in most countries, the opposite holds for the youngest cohort. And, with the exception of Germany and the Netherlands, in the youngest cohort the share of women with tertiary qualifications exceeds that of men. Here the distinctiveness of Germany and the Netherlands is due to the

\footnotetext{
${ }^{3}$ Simpler measures, such as the chi-squared statistic for each origin- destination table divided by the number of cases in the table, show the same trends.
} 
availability of vocational training alternatives in occupations such as childcare, nursing and administration that remain popular with women.

[Figure 5 here]

The association between class origins and education (which we might term "educational equality") is shown in Figure 6.4 In the European countries, the pattern is similar to that for social fluidity. Among men and women alike, educational equality increased up to about the 1945-54 cohort then remained rather constant. But the US, once again, shows a different trend, but in this case it is for men, among whom educational equality increased slightly early in the century, remained unchanged, then reverted to what it was in the oldest cohort. US women, however, followed the same trend as the Europeans.

[Figure 6 here]

Absolute and Relative Mobility in the 20 $20^{\text {th }}$ Century

This review of the two kinds of mobility, absolute and relative, has shown some remarkable similarities in trends among the five countries in our study. Cohorts born before about the middle of the $20^{\text {th }}$ century experienced successively more upward mobility and less downward mobility. In France, Germany, the Netherlands and Sweden they also experienced increasing social fluidity and increasing educational equality. Cohorts born after that point show little change in social fluidity or educational equality (though with some suggestion of a strengthening of the origin - education association among men). As for absolute mobility, among men upward mobility grew less common and downward mobility more, whereas for women, rates of upward and downward mobility

\footnotetext{
${ }^{4}$ In the case of German women we have insufficient observations in the two earliest born cohorts and so they are omissed from this figure.
} 
remained roughly constant. The patterns are slightly different for relative mobility in the US, with men following the same trend as Europe in social fluidity but not in educational equality and women following the same tend in educational equality but not in social fluidity.

In the remainder of this chapter I focus on social fluidity and address the question of what accounts for the trends that we have observed.

\section{Structural Change and Social Fluidity}

The growth in upward mobility and decline in downward mobility that we observe in our earlier born cohorts were the result of structural changes that took place at similar times in these countries and which were particularly pronounced during the period immediately following World War II, when rapid economic growth was driven by a conjunction of events: recovery after the war, recovery from earlier periods of protectionism, the decline in agriculture, technological innovation and, in some European countries, the development of corporatist arrangements (Crafts and Toniolo 2008; see also Judt 2010: 325). This period of almost 30 years was one of historically low rates of unemployment and widespread labour shortages and it was people born between the 1920s and 1950s who were the main beneficiaries. But it came to a halt in the early 1970s, to be replaced, at least in the short term, by inflation, falling growth rates, and growing unemployment.

It is well known from studies of Great Britain that these changes were associated with greater upward mobility (for example, Goldthorpe 2016), particularly into the service class. But it has not been recognised that these structural changes also contributed to greater social fluidity. Figure 7 shows $^{5}$ that, across all birth cohorts, the service class expanded in both origins (dashed line) and destinations. In the earlier born cohorts, the expansion was greater in destinations than origins: thus there was growing "room at the top" which people born outside the service class could occupy. For those born after midcentury, the reverse was true: service class origins grew more quickly than

\footnotetext{
${ }^{5}$ Figures 7 and 9 refer only to men but the patterns for women are the same.
} 
destinations (as the converging of the two lines in Figure 7 shows). The gap between the size of the service class in destinations and origins reached a peak in either the 1934-44 or 1945-54 birth cohort and then began to diminish.

[Figure 7 here]

Fathers of men in the older cohorts would have reached occupational maturity before World War II, a period in which there was relatively little expansion of service class positions. Their sons reached occupational maturity between 1945 and the late 1970s, in a period of marked expansion of service class positions. It was these men who, more or less, became the fathers of the men in the younger cohorts, who, in their turn, had to find jobs in labour markets in which the share of service class positions was growing much more slowly. These uneven patterns of growth at the top of the class structure in the parental and filial generations are an important element in accounting for why the earlier cohorts experienced growth in upward mobility while the younger cohorts have experienced growing downward mobility.

A similar situation is evident in the relationship between tertiary education and service class positions. In the oldest of our cohorts there was a considerable over-supply of service class positions relative to tertiary educated graduates, as Figure 8 shows. This implies that that not only was tertiary education very likely to secure a position in the service class, but also that this class was open to people who lacked tertiary qualifications. In the youngest cohort, however, only in Germany and the Netherlands is there a surplus of service class positions over tertiary graduates.

[Figure 8 here]

As service class destinations expanded in the earlier born cohorts, the odds of people born into the service class staying there (rather than being downwardly 
mobile) remained the same or increased, as the solid line (labelled "Stay") in Figure 9 shows. But the odds of people born outside the service class moving into it (rather than remaining outside it) increased more (the dashed line in Figure 9, labelled "Enter"). The gradual convergence of the two lines in Figure 9 shows that the odds ratio of access to the service class, comparing those born into it with those born outside, diminished. In other words, social fluidity in access to the service class increased as the service class expanded.

[Figure 9 here]

Greater social fluidity requires that more people from higher origins move down or that more people from lower origins move up, or both. When positions at the top are increasing, people can be upwardly mobile even while the chances of staying there for people born into the top classes remain unchanged. But without expansion of the service class, change in both mobility and social fluidity takes on a zero-sum quality: people from non-service origins can only improve their position at the expense of people from service class origins. This latter situation is what we observe in our later born cohorts. As Figure 7 shows, the gap between service class destinations and origins narrowed because, in these cohorts, origins grew faster than destinations. And, as Figure 9 shows, under these circumstances, the convergence in the lines representing the odds for staying and entering the service class ceased and the odds moved roughly in parallel: social fluidity in access to the service class remained constant. Figure 10 shows the evolution of the resulting odds ratio for access to the service class. ${ }^{6}$ There is, once again, a clear pattern of weakening in the association between origins and destinations across the earlier born cohorts, followed by little change in the later cohorts.

[Figure 10 here]

The Role of Education

\footnotetext{
${ }^{6}$ The odds ratio in Figure 10 is normed to have the value of 1 in the first cohort in all the countries. The actual value varies but is everywhere much greater than 1 .
} 
The most straightforward way in which change in education can affect social fluidity is through greater educational equality - that is, a weakening of the association between origins and educational attainment. We call this the effect of educational equalization. But a number of studies, dating back to Hout (1988), have shown that the strength of the association between origins and destinations - social fluidity, in other words - differs between people with different levels of education. This finding has been reported not only for the US but also for Sweden (Breen and Jonsson 2007), France (Vallet 2004) and Germany (Breen and Luijkx 2009), among others. In all these countries the pattern is similar: among those with higher levels of education, the association between origins and destinations is weaker. This means that, as educational attainment increases, a growing share of the population comes to have higher levels of education and so a growing share of the population has origins that are less strongly related to their destinations. Social fluidity can therefore be changed by what Breen and Jonsson (2007) termed a "compositional effect", that occurs when two conditions are met: social fluidity is higher among those with higher levels of education, and education expands to increase the share of the population with these levels of education. In our data we find that the association between origins and destination is indeed weaker at higher levels of education except in the Netherlands.

To what extent have educational equalization and expansion contributed to change in social fluidity? The marked similarity in the trends in social fluidity (shown in Figure 4) and in educational equalisation (Figure 6) suggests that equalisation may have played a role. Figures $11 \mathrm{a}$ and $11 \mathrm{~b}$ shed some light on this. Here, the logarithm of the unidiff value for each cohort in our countries is plotted (in the left panel) against the logarithm of the unidiff coefficient for the origin- education association (educational inequality) and, in the right panel, against the logarithm of the share of people with a tertiary qualification (educational expansion). The strong relationships between social fluidity and both educational equalisation and expansion are evident.

[Figures 11a \& 11b here] 
I explored this is some more detail using a fixed effects regression analysis in which the units of analysis were the cohorts within each of the five countries. The goal was then to assess the relationship between, on the one hand, social fluidity for each cohort and country combination and, on the other, educational equalisation and educational expansion. To explain how the final regression model is developed begin with the equation:

$\log \theta_{i j c}=\varphi_{c} \log \theta_{i j}$, for all $i$ and $j$.

Here $\theta_{i j c}$ is an odds ratio involving origins $i$ and destination $j$ in birth cohort $c$ in a given country, set equal to the unidiff coefficient for that cohort, $\varphi_{c}$ multiplied by the baseline odds ratio, $\theta_{i, j}$.

Then I write $\varphi_{c}$ as a multiplicative function of $\delta_{c}$ (the unidiff coefficient for the origin - education association in cohort $c$ ) and $X_{c}$, (the proportion in cohort $c$ with tertiary education):

$E\left(\varphi_{c}\right)=A \delta_{c}^{\beta_{1}} X_{c}^{\beta_{2}} \Rightarrow$

$E\left(\log \varphi_{c}\right)=a+\beta_{1} \log \delta_{c}+\beta_{2} \log X_{c}$

Further predictors could be added if required. This multiplicative model means that the parameter estimates are not affected by dividing $\varphi_{c}$ and $\delta_{c}$ by the values they take in the first cohort (which we do to normalize them). In both cases this affects the intercept but not the $\beta s$.

We cannot estimate the parameters of the relationship between social fluidity and the predictors across countries and cohorts because baseline fluidity (captured by $\theta_{i j}$ ) differs between countries. But we can estimate the withincountry relationships over cohorts. Our goal is to estimate the averages of these within-country relationships. 
Using $k$ to denote country we have:

$E\left(\log \varphi_{c k}\right)=a_{k}+\beta_{1 k} \log \delta_{c k}+\beta_{2 k} \log X_{c k}$

Because we want the averages of the $\beta s$, I constrain them to be the same in all countries but allow each country to have its own intercept. This gives the country fixed effects model:

$E\left(\log \varphi_{c k}\right)=a_{k}+\beta_{1} \log \delta_{c k}+\beta_{2} \log X_{c k}$

Here $\alpha_{k}$ is the fixed effect for each country, $\beta_{1}$ is the partial average (across countries) relationship between educational equalisation and social fluidity, and $\beta_{2}$ is the partial average relationship between educational expansion and social fluidity. The data are weighted according to the number of individuals in each cohort and country combination: 30 combinations for men and 28 for women. Separate models are fitted for men and women. It should be kept in mind that these estimates are averages across the countries and so they tell us nothing about how equalization or expansion might have affected fluidity differently in each of them.

For the model shown in equation (1) the estimate of $\beta_{1 k}$ (the coefficient for educational equalisation) was 0.37 (standard error 0.20 ) for men and $0.62(0.27)$ for women. The estimate of $\beta_{2 k}$ (the coefficient for educational expansion) was $0.10(0.05)$ for men and -.06 (0.07) for women. These were unchanged when I added GDP per capita to control for economic growth or a measure of the difference in the size of the service class in origins and destinations as a control for structural change. The estimates tell us that a $10 \%$ difference in the origin education unidiff parameter is, averaging across all five countries, associated with a $4 \%$ difference in social fluidity among men and a 6\% difference among women. For men a $10 \%$ expansion in the share with tertiary education is association with just over a $1 \%$ increase in social fluidity. But among women, expansion has only a weak association with fluidity (controlling for 
equalisation). The fact that these estimates remain the same when I control for structural change (in some cases growing larger) suggests that, although the largest changes in social fluidity occurred in the cohorts in which structural changes were greatest, the impact of educational expansion and equalization was not confined to them.

The question naturally arises of whether the relationship that we have found between education and social fluidity exists because education actually affects social fluidity: are changes in education one of the causes of changes in fluidity? It is nowadays widely held that establishing a relationship of cause and effect requires an analysis that mimics a randomized control trial as closely as possible. We cannot do that and so, by such a criterion, our results are descriptive. Nevertheless, the respondents to the surveys we use are interviewed when they are, on average, in their early forties and for the most part they completed their education around 20 years earlier. Thus the increasing openness and the expansion of education is related to social fluidity measured 20 years later. This rules out any reverse causality, but it also makes it difficult to imagine what factors might render the association non-causal because they would have to have caused educational change and, 20 years later, a weaker origin - destination association.

Further evidence on the role played by education in changing social fluidity comes from the results of simulations carried out for each country employing a method introduced by Breen (2010) to examine the extent to which educational equalisation and expansion, among other things (including changes in the returns to education), could have generated the observed trend of social fluidity over cohorts.

Figures $12 \mathrm{a}$ and $\mathrm{b}$ show how well a simulated trend in social fluidity, assuming that this trend was driven only by educational equalisation and expansion, reproduces the observed trend (from Figure 4). In Germany, France and Sweden (Figure 12a) the simulation is very close to the actual trend, showing that equalisation and expansion were capable of generating the changes in social 
fluidity that we observed. The simulations fare less well in the US and the Netherlands (Figure 12b) where they consistently understate fluidity. In the Dutch case, and for men in the US, the decline in fluidity is underestimated and, among US women, educational equalisation and expansion seem to have had no bearing on the trend in social fluidity. Allowing for change over cohorts in the relationship between education and class destinations (change in the class returns to education) fails to account for the gap in any of these cases.

[Figures $12 \mathrm{a}$ and $12 \mathrm{~b}$ here]

Conventionally this gap would be interpreted as showing the impact of changes in the direct effects of origins on destinations, net of education. But since we have no information on what these might be, interpreting it would be no more than speculation.

\section{Conclusions}

There was a sharp contrast in the fortunes of people before and after the 1950s. Among those born in the second quarter of the 20th century upward mobility rates increased as positions at the top of the class structure, in the service class or 'salariat', became more numerous, with a growing surplus of service class destinations over service class origins. At the same time, social fluidity increased: the chances of entering a more desirable class, and avoiding a less desirable one, became more equal between people of different class backgrounds. There were parallel developments in education. Not only did educational provision expand and average attainment increase, there was also a weakening in the extent to which class origins determined how much education someone attained. All these changes were common to both sexes, though educational upgrading and the growth in upward mobility were more pronounced among women. In contrast, among cohorts born after mid-century, social fluidity has not continued to increase (but neither has it declined), while upward mobility has become less common and rates of downward mobility have increased. The picture for women has to be modified somewhat: improvements in upward mobility and social fluidity persisted longer. Overall, women's 
position improved more than men's, though important differences remain. In particular, although the share of men and women in the service class has become more equal, women are still much more likely than men to be found in the lower (class II) rather than the upper (class I) service class.

Much research into intergenerational mobility has addressed two rival hypotheses. Modernisation theory argues that, as societies develop, the forces of competition drive institutions to become more meritocratic (see, for example, Ganzeboom, Luijkx and Treiman 1989 and Treiman 1970). ${ }^{7}$ The proponents of the rival view - sometimes called "trendless fluctuation" - claim that the modernisation argument neglects the degree to which those in advantaged positions can secure similarly advantaged positions for their children, despite the forces of modernisation (Erikson and Goldthorpe 1992; Goldthorpe 2000, chapter 11). Given information only on cohorts born in the first half of the century we would have concluded that the former was strongly supported. Data from only the cohorts born in the later part of the century would have given support to the "trendless fluctuation" hypothesis. Taken as a whole our analysis casts doubt on the accuracy of both of these generalizations and shows the advantages of taking a long-term perspective on intergenerational mobility and how it evolves.

The hypothesis that comes closest to capturing the reality of mobility trends in the $20^{\text {th }}$ century is that of Lipset and Bendix: "Since a number of the countries for which we have data have had different rates of economic expansion but show comparable rates of social mobility, our tentative interpretation is that the social mobility of societies becomes relatively high once their industrialization, and hence their economic expansion, reaches a certain level" (Lipset and Bendix 1959: 13). Strictly speaking this claim is wrong, because rates of mobility, measured as the proportion of people in a destination different from their origin, changed little over the $20^{\text {th }}$ century. But the spirit of their argument - that

\footnotetext{
${ }^{7}$ For example, Ganzeboom and De Graaf (1984) predicted that, based on trends between 1954 and 1977, the Netherlands would reach perfect mobility by 2023 (see also Ganzeboom and Luijkx 2004: 345).
} 
economic expansion delivers a one-time boost to mobility - seems substantially correct if we take it to refer to upward mobility or, indeed, to social fluidity.

The historical perspective sheds light on the decline in upward mobility and the lack of any further equalisation of mobility chances among people from different social origins in the second half of the $20^{\text {th }}$ century. To a degree, these are the fruit of earlier achievements. People born in the later part of the 20th century are largely the children of people in the birth cohorts that enjoyed unprecedented rates of upward mobility. The decline of upward mobility among them is not the result of a reduction in the number of places at the top of the class structure: in some countries, such as the Netherlands, the share of each birth cohort in service class destinations has continued to increase. Rather, the explanation lies in the increasing rate of growth in service class origins.

Explanations for the ending of the trend towards ever-greater fluidity must be found in two areas. First, the association between origins and education has changed little in later born cohorts, and changes in this association have been an important factor in driving social fluidity. Second, the increases in fluidity experienced by people born in the second quarter of the century were facilitated by the massive structural changes that occurred in the immediate post-war period, especially the growth of the service class. The prospects for addressing the lack of growth in social fluidity thus depend on the prospects for further structural change and further equalization of education. As far as the former is concerned, the outlook is not promising:

In particular, it has to be recognized that there is no policy route back to the structural conditions of the mid-twentieth century. The very substantial growth in demand for professional and managerial personnel that then occurred was created by an historic shift in the scale of public administration, of health, education and social welfare provision, and of industrial and commercial organization that could scarcely be repeated. It follows therefore that for the years ahead policy will have to be directed towards increasing mobility through increasing social fluidity (Goldthorpe and Jackson 2007). 
In relation to the latter, it is important to consider the changed circumstances under which further educational equalization would have to occur. At the start of the 20th century, most people had a very low level of educational attainment and so the improvement in educational attainment and the equalization of educational outcomes was mostly due to children from working and farming classes increasing the length of time they remained at school (see Breen et al. 2009 and 2010). Policy changes account for some of this. Raising the minimum school leaving age, for example, will reduce inequality at the bottom of the educational distribution because it will eradicate class differentials up to the school leaving age, and it will also diminish the additional number of years needed to gain post-compulsory qualifications. Of greater importance, however, may have been reductions in the barriers to continuing in education (through the removal of school fees, improving access to schools, and the opening up of what had been dead-end tracks) and the incentive of growing returns to higher levels of education that came about because of shifts in the occupational structure, especially from farming to manufacturing and services.

The stagnation in more recent cohorts in the association between class origins and educational attainment has occurred against a different background. Inequalities have shifted from lower educational levels to upper secondary and tertiary education and, whereas in the early 20th century a large share of the population was educationally disadvantaged, now a large share of the population reaches tertiary education. The composition of the educationally disadvantaged has also changed. The unskilled working class is not only smaller than it was, it is also more highly selected, being made up of families that did not benefit from the post-war surge in upward mobility and which may even have been downwardly mobile. This suggests that they might have particular disadvantages linked to individual characteristics or circumstances (such as living in poor neighbourhoods or economically distressed regions). Furthermore, in several countries, immigrants nowadays make up substantial shares of families in classes V, VI and VII/IIIb. In the first half of the $20^{\text {th }}$ century, educational equalization came about through improving the education 
of the majority: in the $21^{\text {st }}$ century equalization will require improving the education of a minority.

There is variation among our countries in the degree to which educational expansion persisted throughout the $20^{\text {th }}$ century. In the US, for example, there has been little or no net expansion in education among cohorts born after the 1950s, whereas in France and Germany expansion continued throughout the later part of the $20^{\text {th }}$ century and into the $21^{\text {st }}$. In these and other countries, educational expansion could lead to greater social fluidity if the pattern of a weaker origin - destination association at higher levels of education persisted. The concern here, however, is that, as countries reach a situation in which the majority of each birth cohort acquires tertiary education, the scope for further expansion to weaken the links between class origins and class destinations may become increasingly limited.

The lack of a pathway to greater social fluidity through structural change, educational equalization or educational expansion suggests we should instead, or in addition, seek to reduce the consequences of class position for life chances. In recent decades, of course, the trend has been quite the opposite, with increasing income inequality in many countries driving classes further apart in their life chances. Policies to increase equality of condition have fallen out of favour, and the argument that equality of opportunity legitimates inequality of outcomes has been widely made. But that claim can no longer be taken seriously. Given the limited extent to which equality of opportunity exists, and the uncertain prospects of increasing it, the case for a renewed emphasis on securing greater equality of condition is compelling. 
References

Barone, Carlo and Raffaele Guetto. 2018. Education and Social Fluidity in Contemporary Italy: an analysis of Cohort Trends. In R. Breen and W. Müller (eds). Education and Intergenerational Social Mobility in Europe and the United States.

Betthäuser, B. 2017. "Fostering equality of opportunity? Compulsory schooling reform and social mobility in Germany", European Sociological Review 33: 633644.

Blanden, J., Gregg, P. and Machin, S. 2005. Intergenerational Mobility in Europe and North America. Centre for Economic Performance, London School of Economics.

Breen, R. 2005. Foundations of a neo-Weberian class analysis. Pages 31-50 in Wright, E $O$ (ed.) Approaches to Class Analysis. Cambridge: Cambridge University Press.

Breen, R. 2010. Educational Expansion and Social Mobility in the 20th Century. Social Forces. 89(2): 365-388.

Breen, R. and Jonsson, J. O. 2005. Inequality of Opportunity in Comparative Perspective: Recent Research on Educational Attainment and Social Mobility. Annual Review of Sociology. 31: 223-243.

Breen, Richard and Jan 0. Jonsson. 2018. Sweden, the middle way? Trends and Patterns in Social Mobility and Educational Inequality. In R. Breen and W. Müller (eds). Education and Intergenerational Social Mobility in Europe and the United States.

Breen, R. and Luijkx, R. 2007. Social mobility and education: a comparative analysis of period and cohort trends in Britain and Germany. Pages 106-126 in 
Scherer S et al. (eds.) From Origin to Destination: Trends and Mechanisms in Social Stratification Research: Frankfurt: Campus.

Breen, R., Luijkx, R., Müller, W. and Pollak, R. 2009. Nonpersistent inequality in educational attainment: Evidence from eight European countries, American Journal of Sociology, 114: 1475-1521.

Breen, Richard, Ruud Lujkx and Eline Berkers. 2018. The role of Education in the Social Mobility of Dutch cohorts, 1908-1974. In R. Breen and W. Müller (eds). Education and Intergenerational Social Mobility in Europe and the United States.

Breen, R., Luijkx, R., Müller, W. and Pollak, R. 2010. Long-term trends in educational inequality in Europe: Class inequalities and gender differences, European Sociological Review, 26: 31-48.

Buscha, F. and Sturgis, P. 2015. Increasing inter-generational social mobility: is educational expansion the answer? The British Journal of Sociology. 66: 512533.

Causa, O. and A. Johansson. 2010. Intergenerational Social Mobility in OECD Countries. OECD Journal: Economic Studies, 2010: 1-44.

Crafts, N. F. and Toniolo, G. 2008. European economic growth, 1950-2005: an overview. CERP Discussion Papers No 6863. London: Centre for Economic Policy Research.

Erikson, R. and Goldthorpe, J. H. 1992. The Constant Flux: A Study of Class Mobility in Industrial Societies. Oxford: Clarendon Press.

Esping-Andersen, G. 1990. The Three Worlds of Welfare Capitalism. Princeton, NJ: Princeton University Press. 
Ganzeboom, H.B.G. \& De Graaf, P. 1984. Intergenerational mobility in the Netherlands in 1954 and 1977: a log linear analysis. In: B.F.M. Bakker, J. Dronkers \& H. Ganzeboom (Eds.). Social Stratification and Mobility in the Netherlands, (pp. 71-90). Amsterdam: SISWO.

Ganzeboom, H. B. G. and Luijkx, R. 2004. Recent trends in intergenerational occupational class reproduction in the Netherlands 1970-99. Pages 345-381 in Breen, R (ed.) Social Mobility in Europe. Oxford: Oxford University Press.

Ganzeboom, H. B., Luijkx, R. and Treiman, D. J. 1989. Intergenerational class mobility in comparative perspective, Research in Social Stratification and Mobility, 8: 3-79.

Gil-Hernández, Carlos J. , Fabrizio Bernardi, Ruud Luijkx and Leire Salazar. 2018. Intergenerational Social Mobility in Spain between 1945 and 2006: Educational Expansion without Equalization? In R. Breen and W. Müller (eds). Education and Intergenerational Social Mobility in Europe and the United States.

Goldthorpe, J. H. 2000. On Sociology: Numbers, Narratives, and the Integration of Research and Theory. Oxford: Oxford University Press.

Goldthorpe, J. H. 2016. Social class mobility in modern Britain: changing structure, constant process. Journal of the British Academy 4: 89-111.

Goldthorpe, John H. and Michelle Jackson 2007. Intergenerational Class Mobility in Contemporary Britain: Political Concerns and Empirical Findings. The British Journal of Sociology 58: 525-46.

Hall, P. A. and Soskice, D. 2003. Varieties of capitalism and institutional complementarities. In: Franzese R., Mooslechner, P. and Schürz, M. (Eds.), Institutional Conflicts and Complementarities. New York: Springer, 43-76. 
Hout, M. 1988. More Universalism, Less Structural Mobility: The American Occupational Structure in the 1980s. American Journal of Sociology. 93: 13581400 .

Judt, T. 2010. Postwar: A History of Europe Since 1945. London: Vintage Books.

Lipset, Seymour Martin and Reinhard Bendix. 1959. Social Mobility in Industrial Society. Berkeley: California University Press.

Mayer, S.E. and L.M. Lopoo. 2008. Government Spending and Intergenerational Mobility. Journal of Public Economics. 92: 139-158.

Müller, W. and Haun, D. 1994 Bildungsungleichheit im sozialen Wandel. Kölner Zeitschrift für Soziologie und Sozialpsychologie. 46: 1-42.

Müller, W. and Pollak, R. 2004 Social mobility in West Germany. The long arm of history discovered? Pages 77-113 in Breen, R. (ed.) Social Mobility in Europe. Oxford: Oxford University Press.

Pollak, Reinhard and Walter Müller. 2018. Education as an Equalizing Force: How Declining Education Inequality and Educational Expansion have contributed to more Social Fluidity in Germany. In R. Breen and W. Müller (eds). Education and Intergenerational Social Mobility in Europe and the United States.

Rauscher, E. 2016. Does Educational Equality Increase Social Mobility? Exploiting Nineteenth Century US Compulsory Schooling Laws. American Journal of Sociology. 121: 1697-1761.

Shavit, Yossi, and Hans-Peter Blossfeld (Eds.). 1993. Persistent Inequality: Changing Educational Attainment in Thirteen Countries. Boulder (Colorado): Westview Press. 
Treiman, D. J. 1970. Industrialization and social stratification, Sociological Inquiry, 40: 207-234.

Vallet, L.-A. 2004. Change in Intergenerational Class Mobility in France from the 1970s to the 1990s and its Explanation: An Analysis Following the CASMIN Approach. Pages 115-147 in Breen R (ed.) Social Mobility in Europe. Oxford: Oxford University Press.

Vallet, Louis-André. 2018. Intergenerational Mobility and Social Fluidity in France over Birth Cohorts and Age: The Role of Education. In R. Breen and W. Müller (eds). Education and Intergenerational Social Mobility in Europe and the United States. 
FIGURES

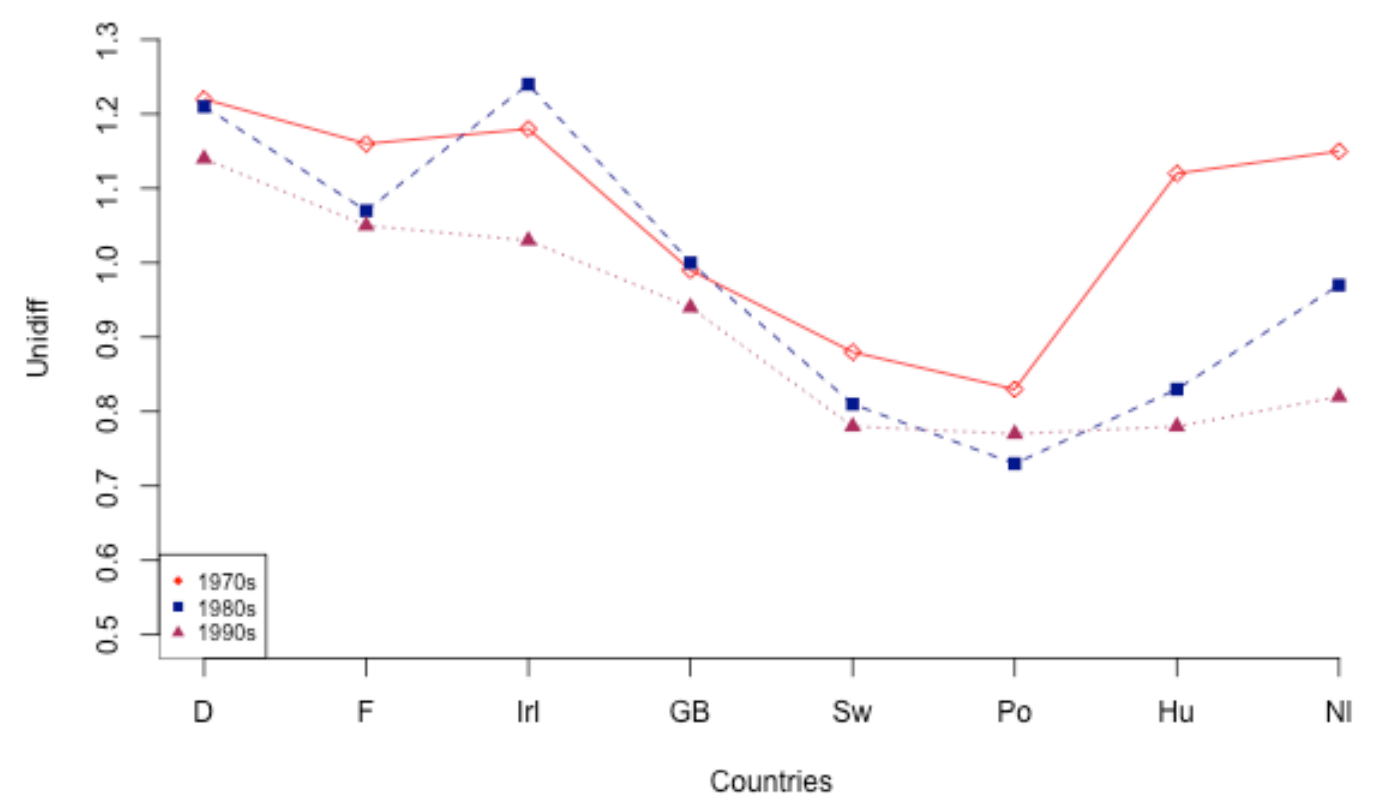

Figure 1: Origin-Destination Class Association among Men in 8 European Countries in the late $20^{\text {th }}$ Century

Men

$\%$ Classes I \& II

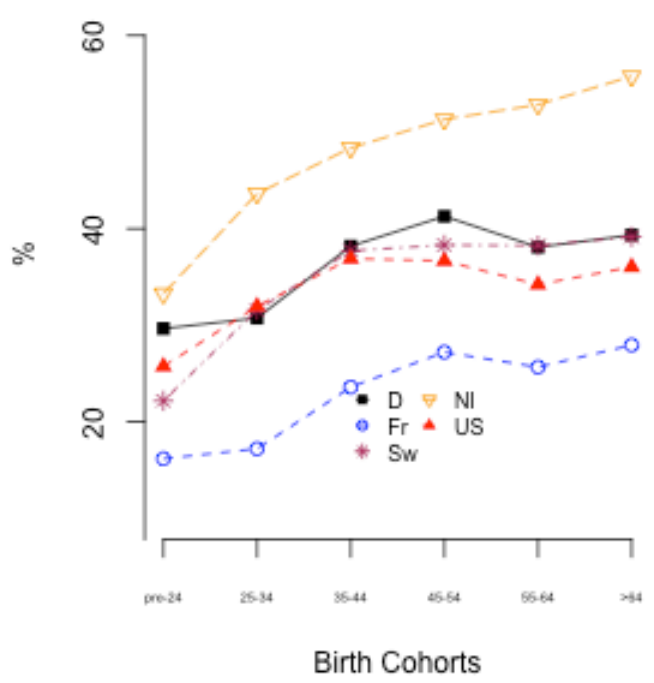

\% Unskilled Manual Class

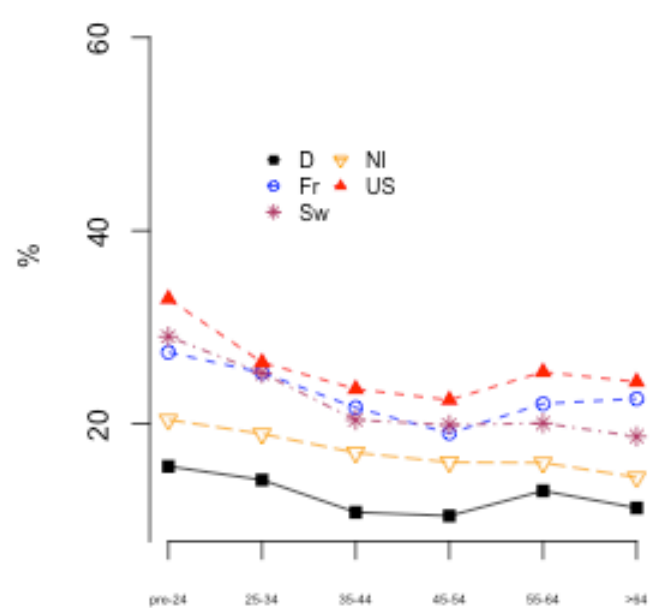

Birth Cohorts

Figure 2a: Share of Men in Highest and Lowest Social Classes by Birth Cohort 


\section{Women}

$\%$ Classes I \& II

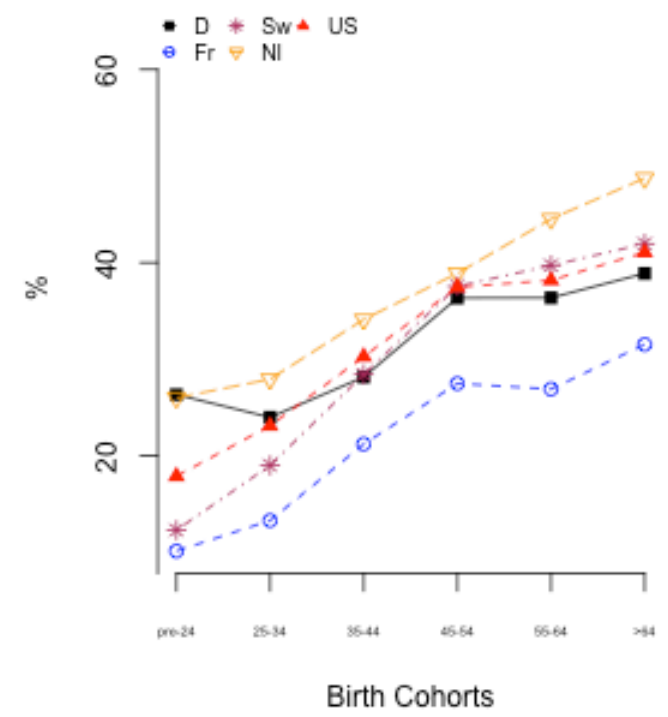

$\%$ Unskilled Manual Class

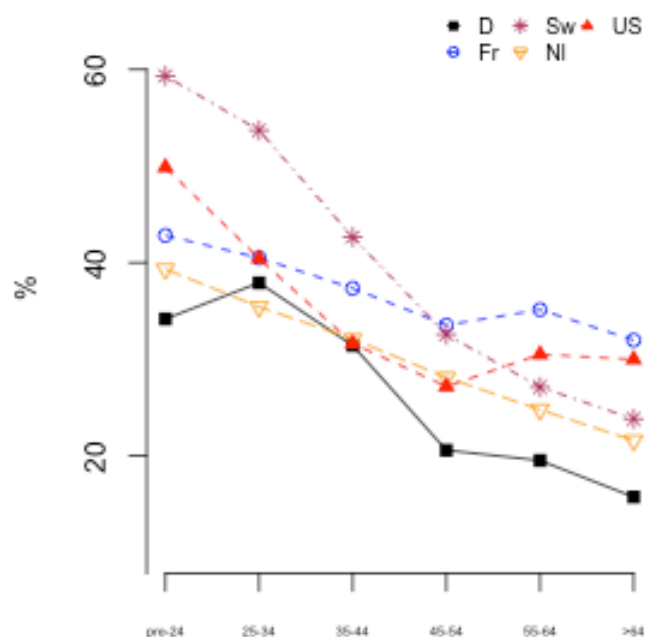

Birth Cohorts

Figure 2b: Share of Women in Highest and Lowest Social Classes by Birth Cohort

\section{Men}

Upward Mobility

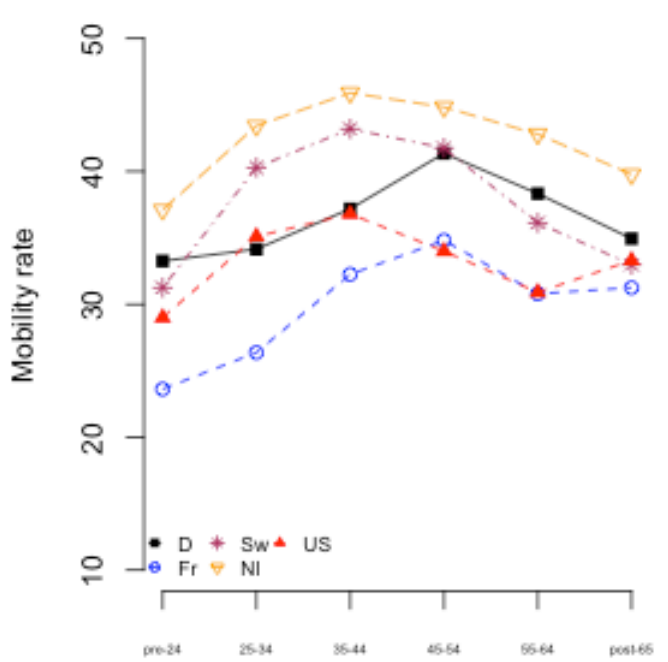

Birth Cohorts
Downward Mobility

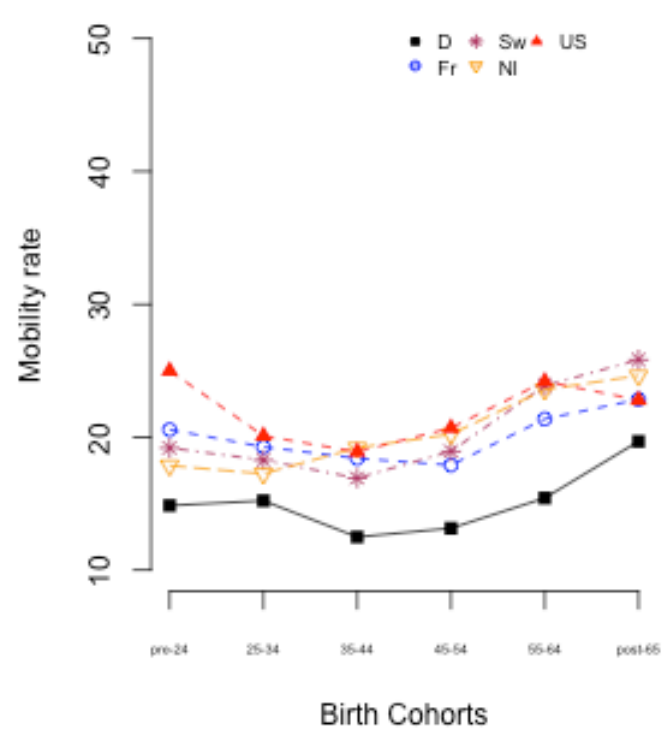


Figure 3a: Upward and Downward Mobility by Birth Cohort, Men 


\section{Women}
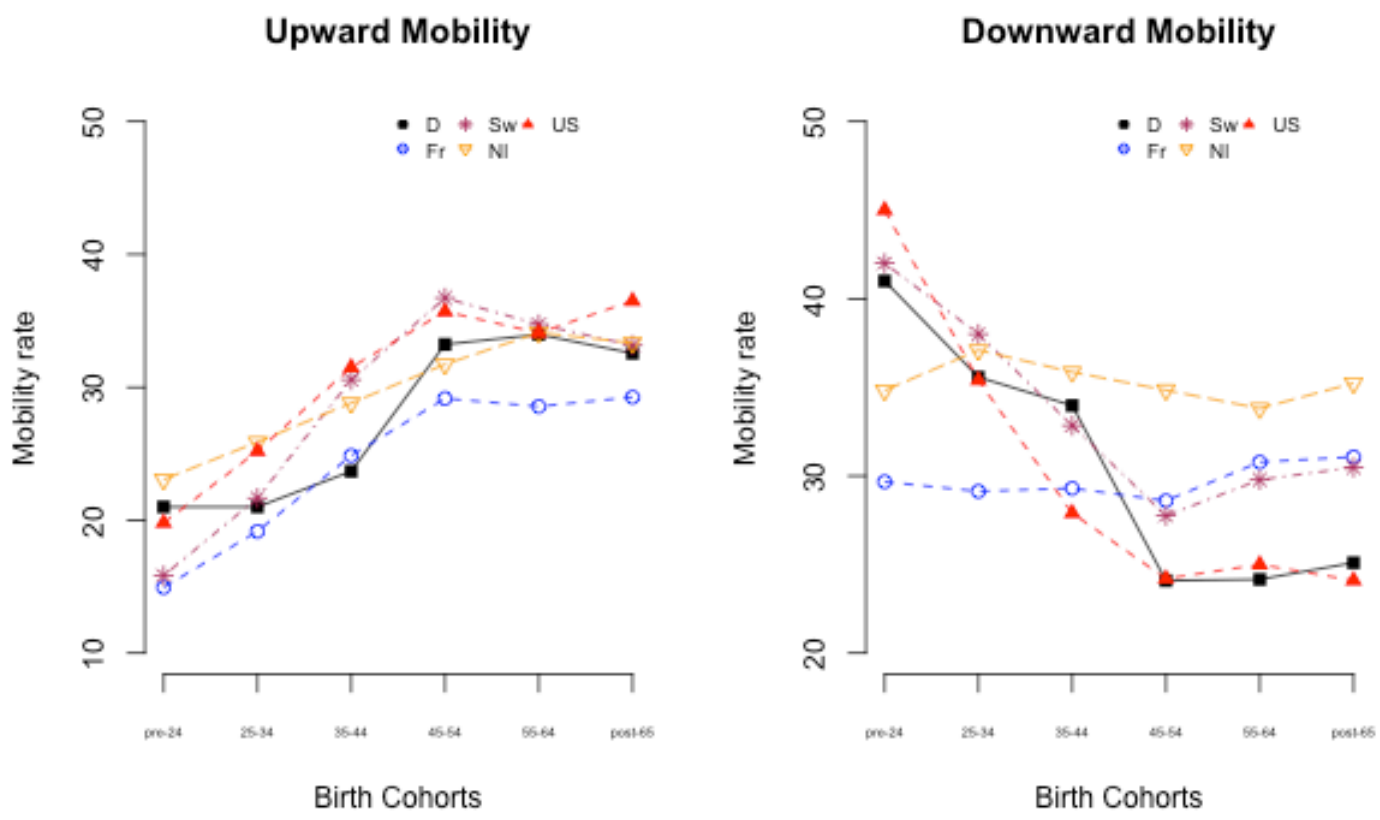

Figure 3b: Upward and Downward Mobility by Birth Cohort, Women 
Men

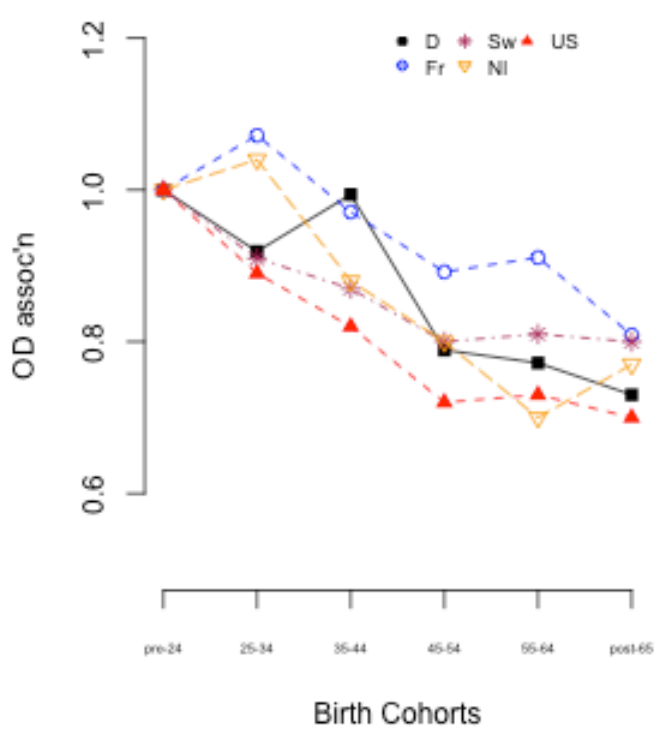

Women

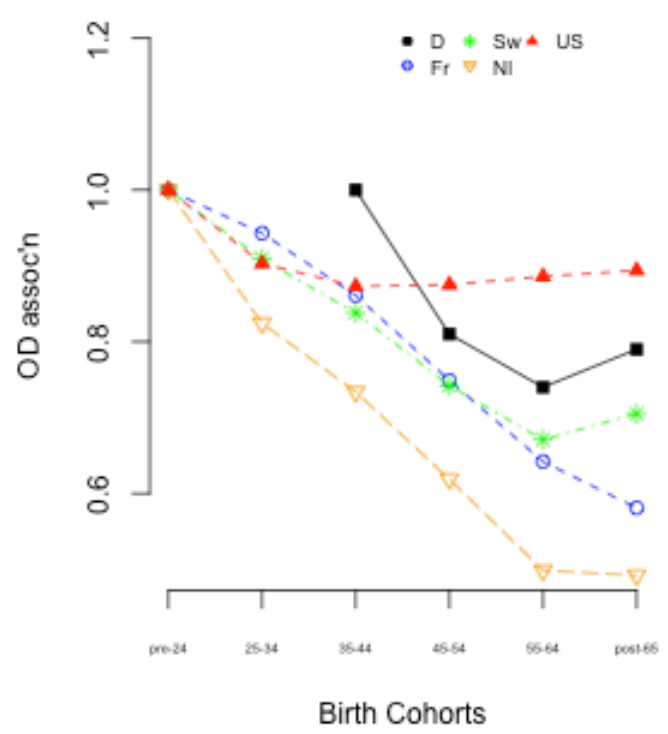

Figure 4: Origin - Destination Unidiffs, Men and Women 
Figure 5a: Shares of Men with Low and High Education

\section{Men}

\section{Elementary}

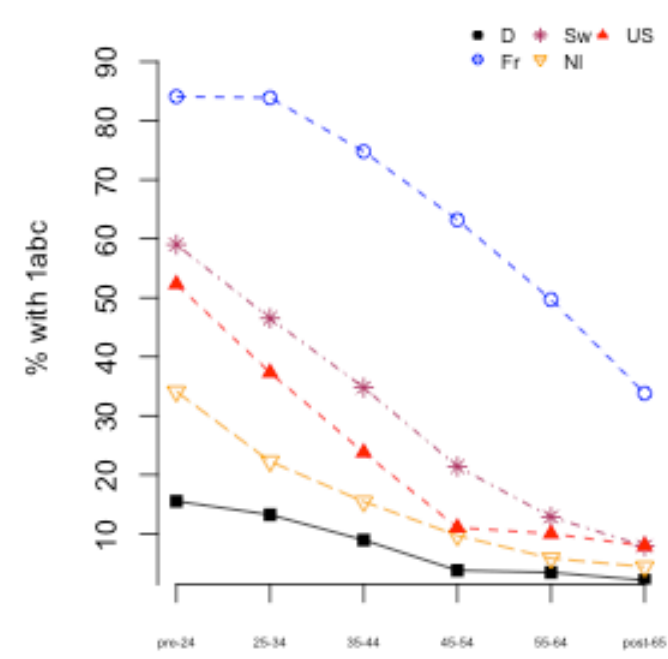

Birth Cohorts
Tertiary

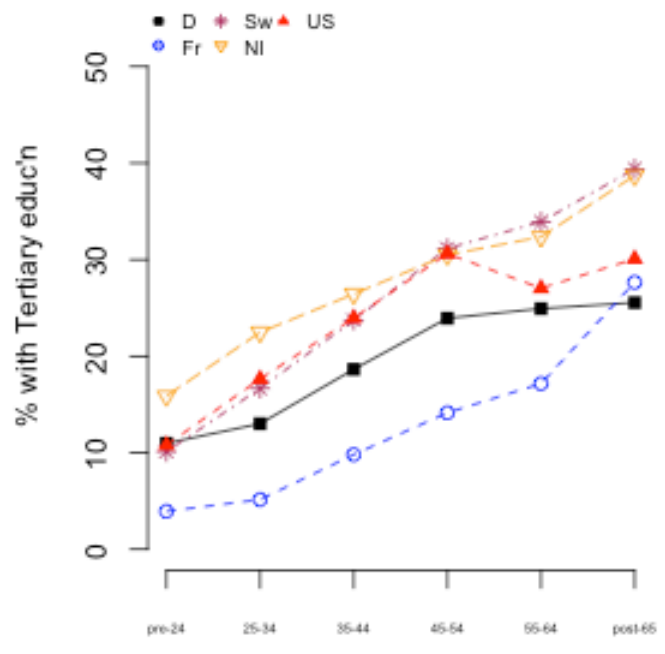

Birth Cohorts

\section{Women}

\section{Elementary}

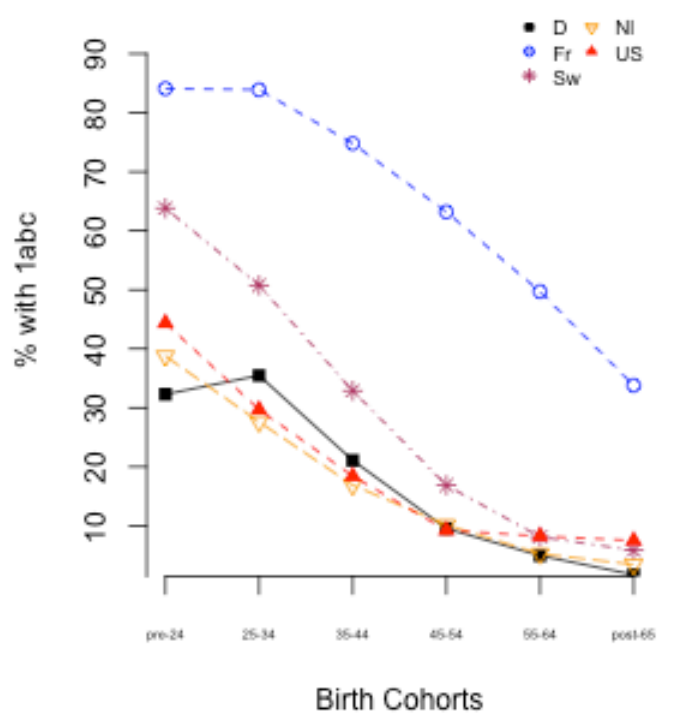

Tertiary

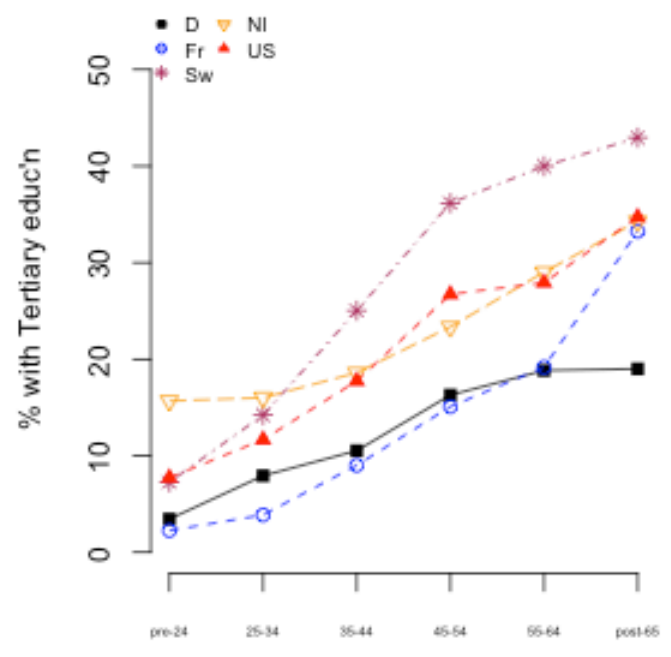

Birth Cohorts

Figure 5b: Shares of Women with Low and High Education 

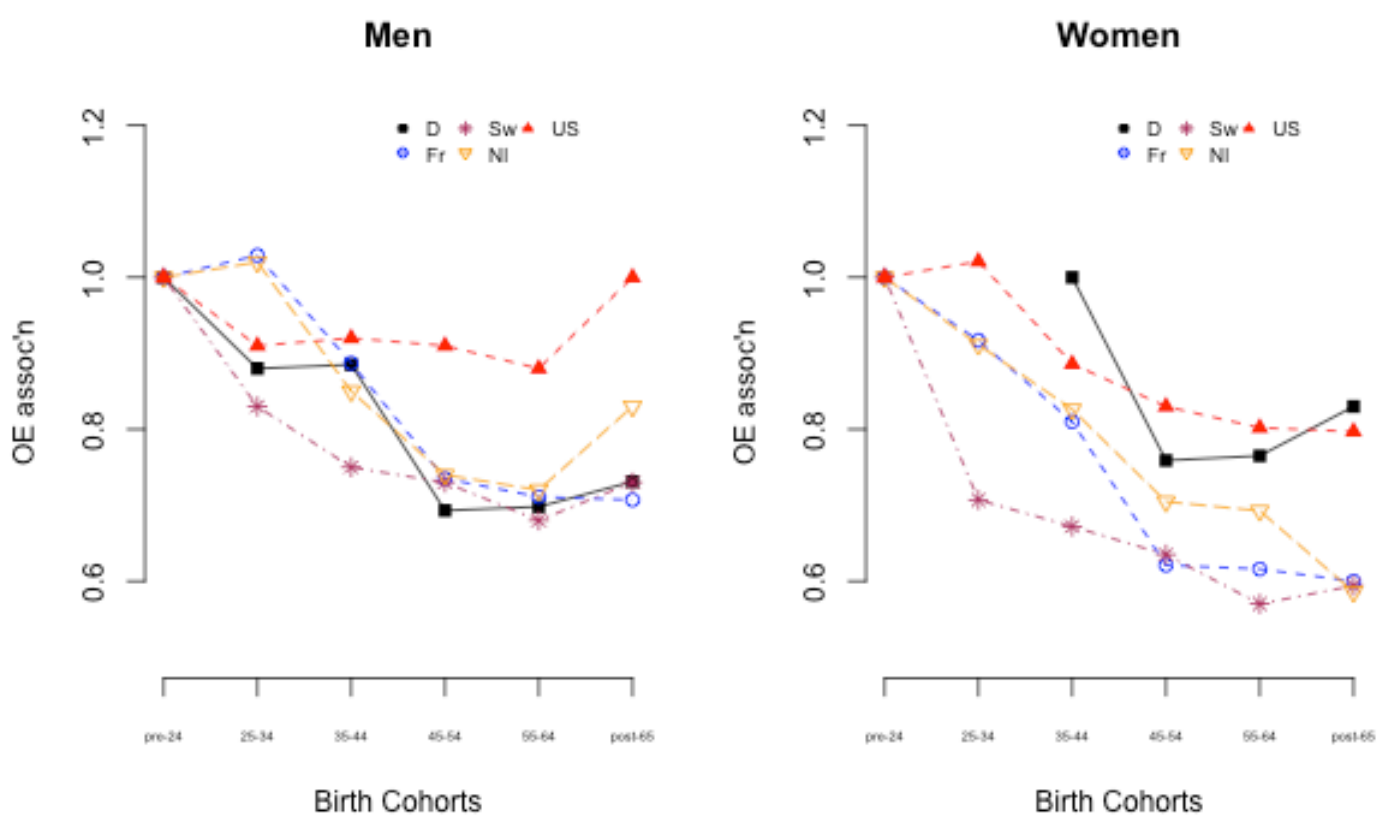

Figure 6: Origin - Education Unidiffs, Men and Women
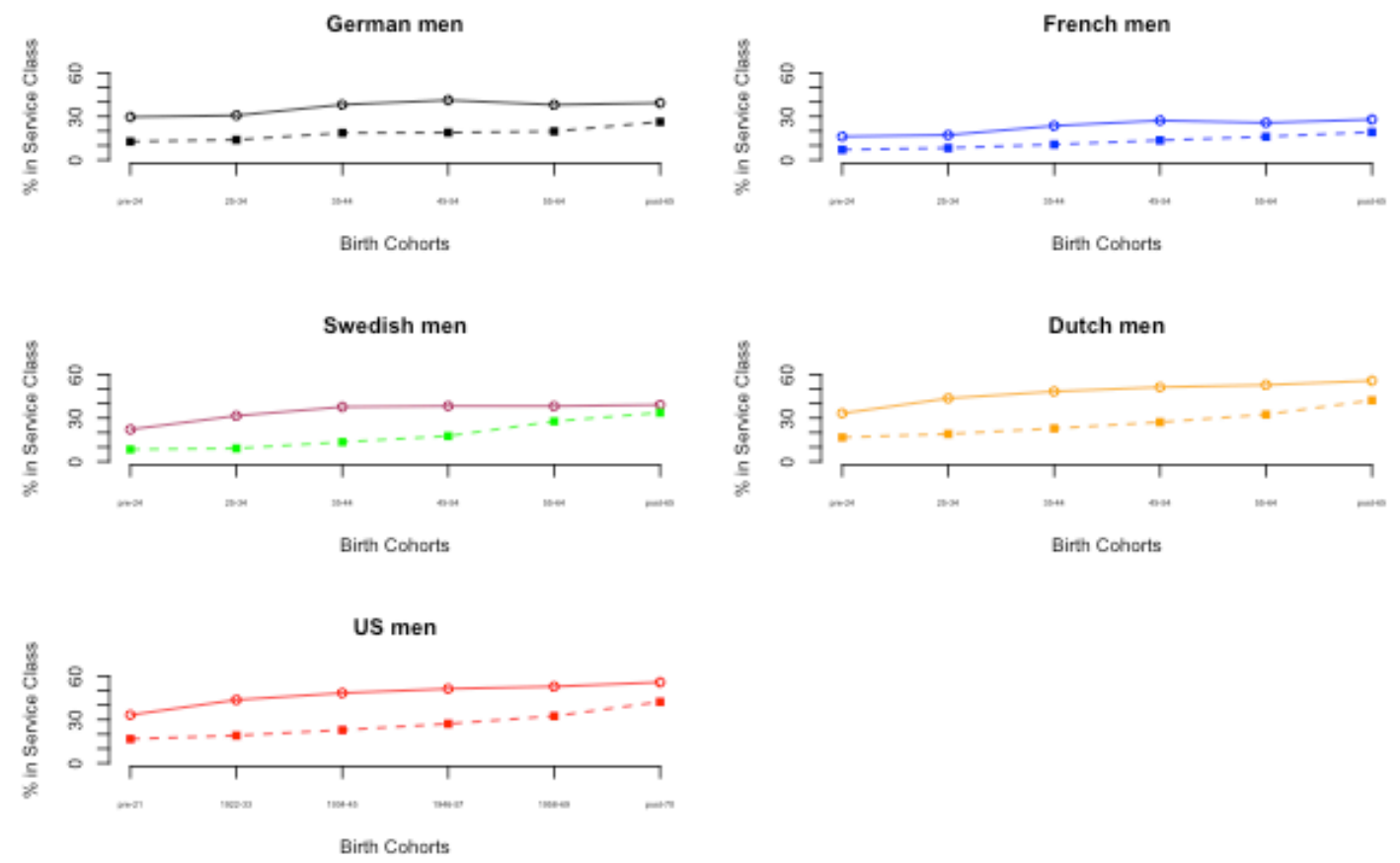

Figure 7: Size of the Service Class in Origins and Destinations by Birth Cohort, Men 
Men

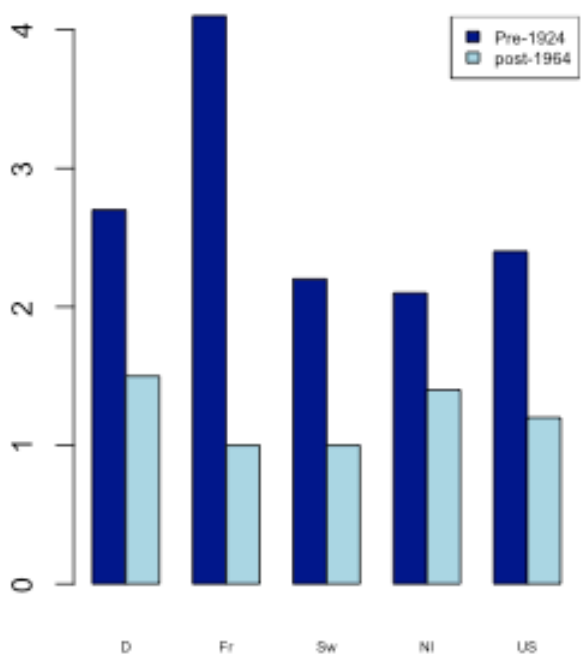

Women

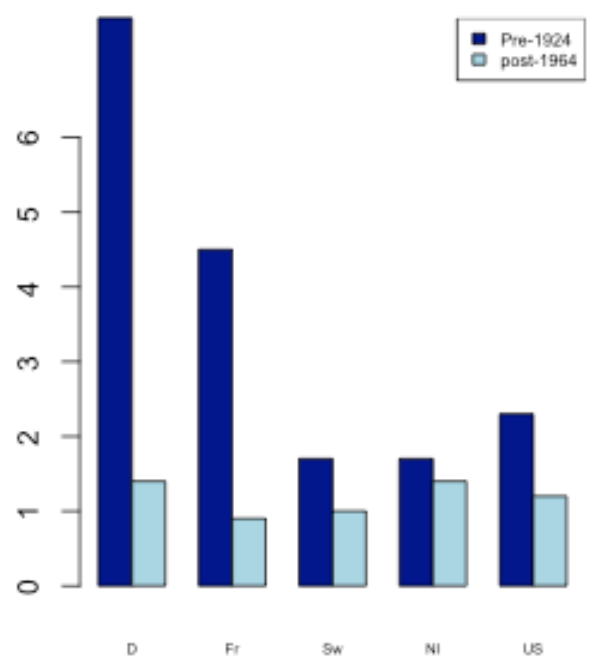

Figure 8: Share with Tertiary Qualifications relative to Share in Service Class, Men and Women in the Oldest ad Youngest Cohorts.

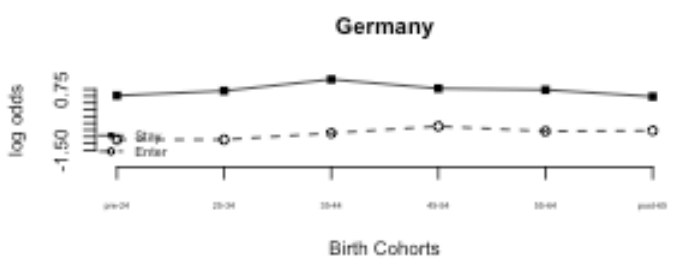

Sweden

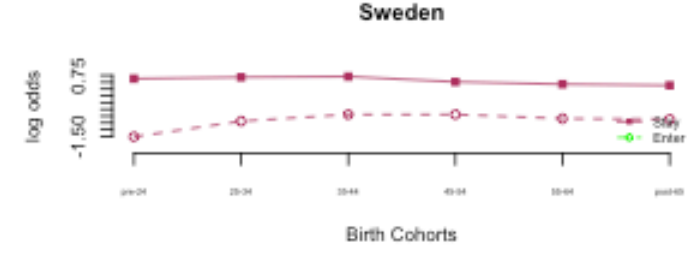

us

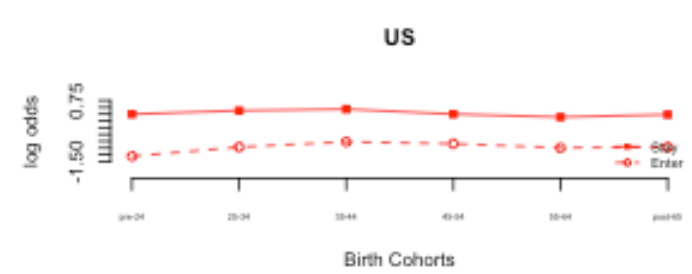

Figure 9: Log odds of Staying in and of entering Service Class
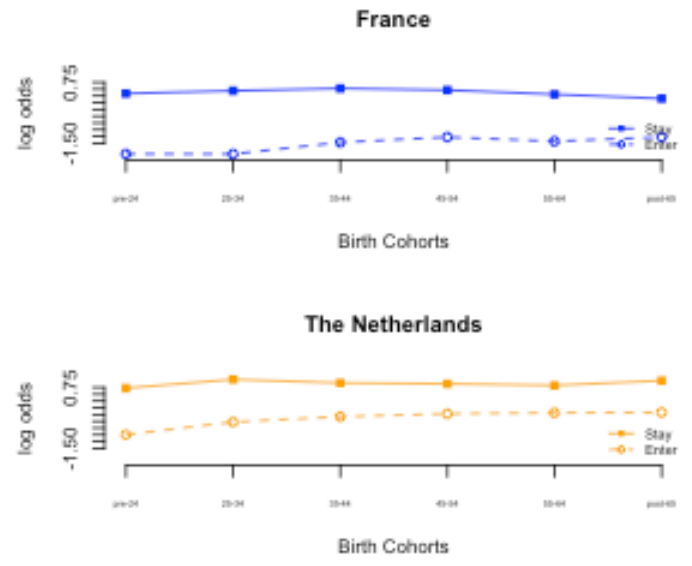

Birth Cohorts 

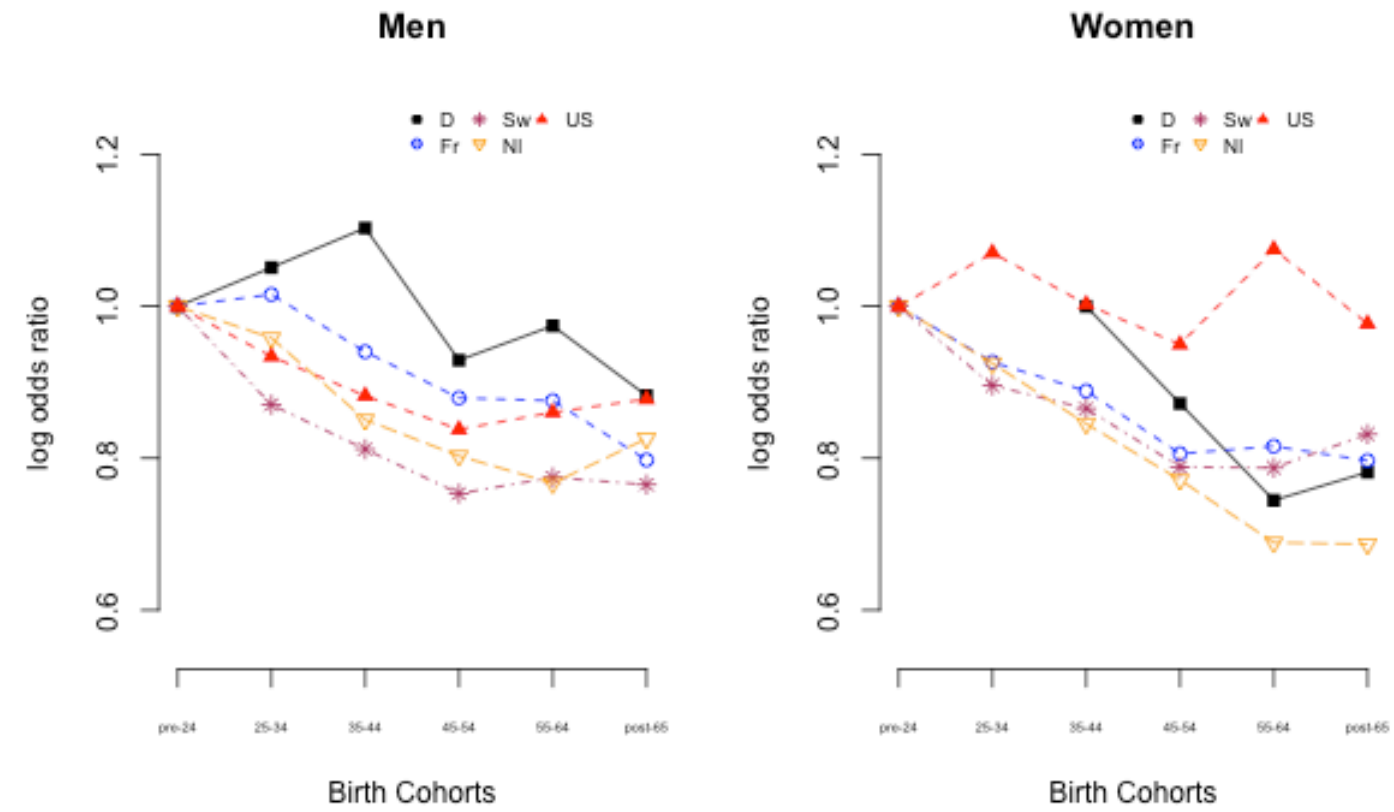

Figure 10: Service class normed log-odds ratio, men and women.

\section{Men}
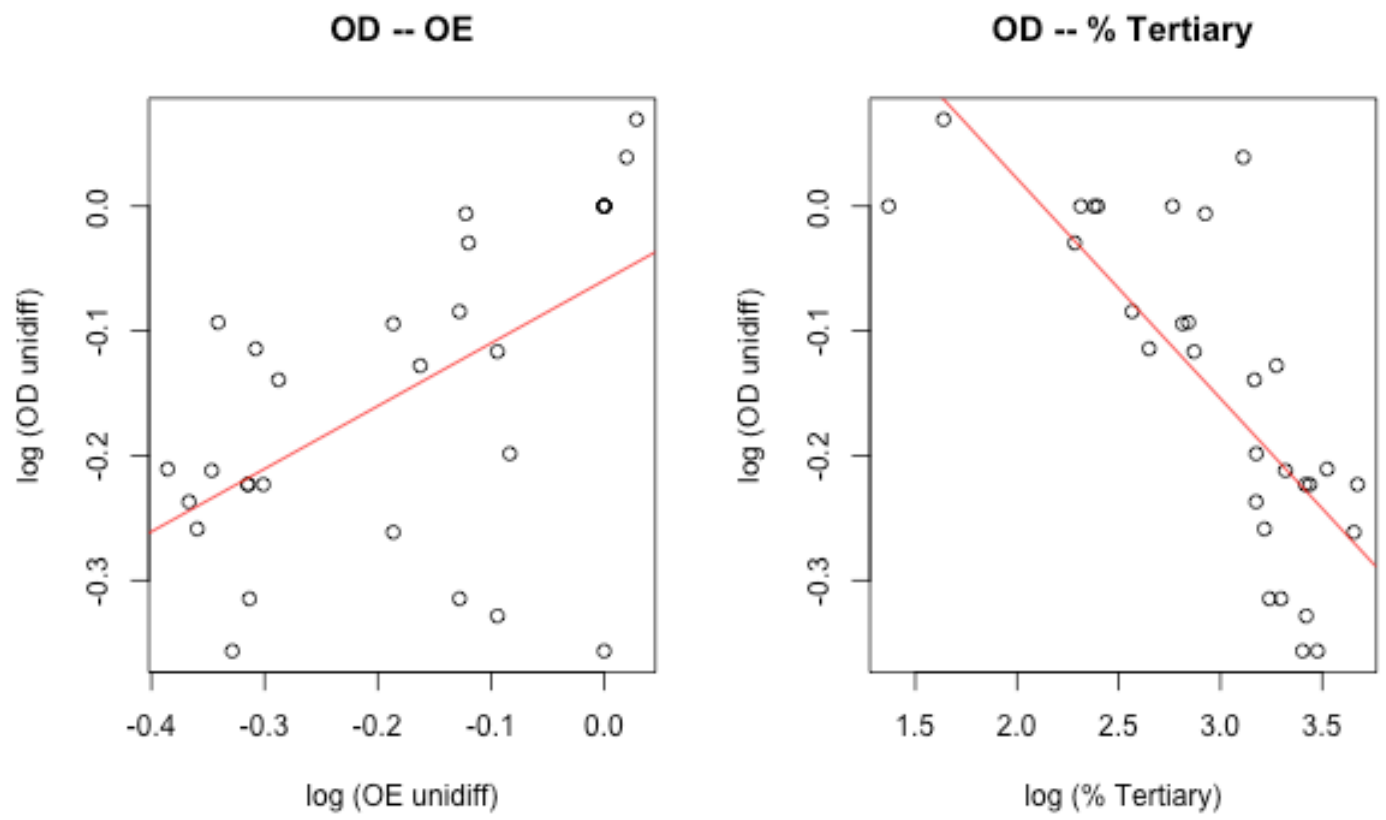

Figure 11a: OD—OE and OD-\% with Tertiary Education, Men. 


\section{Women}
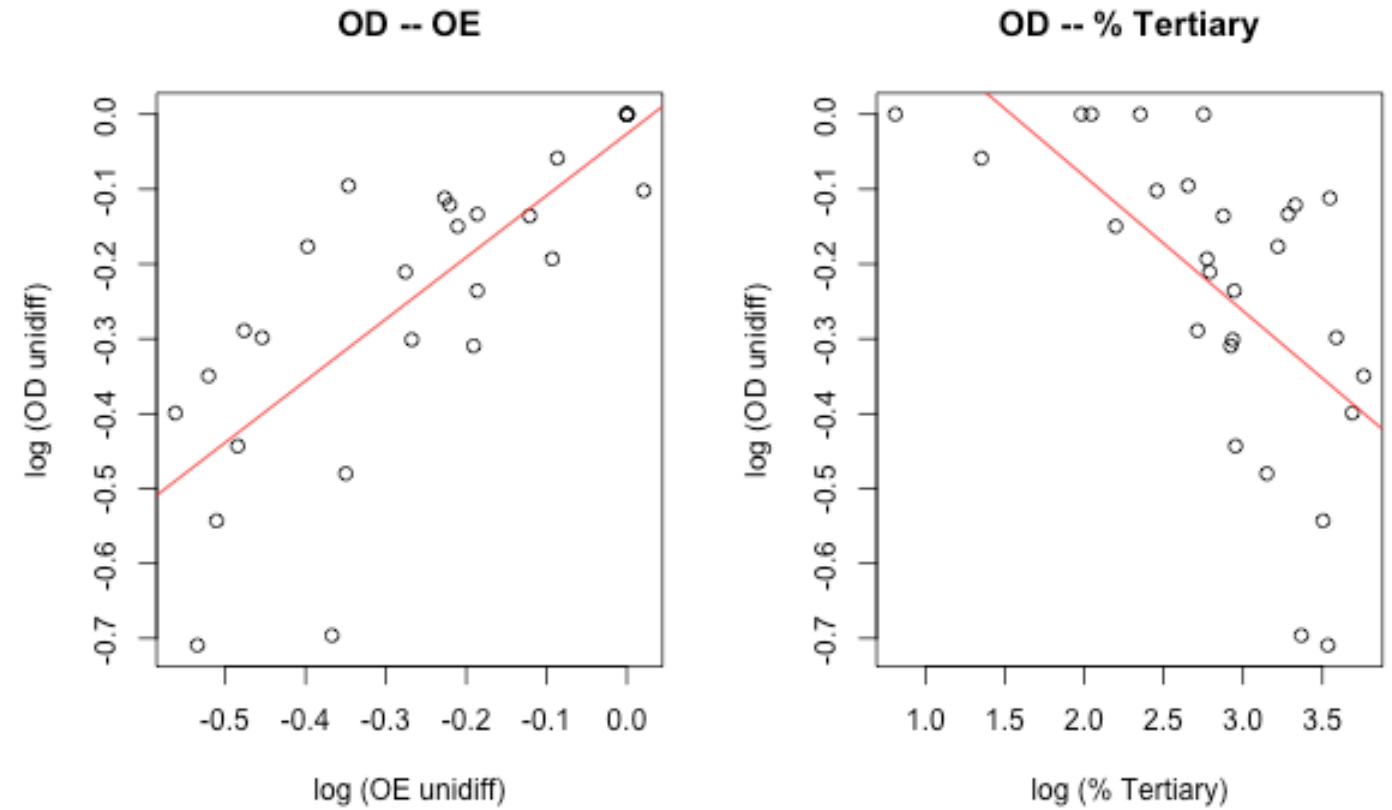

Figure 11b: OD_-OE and OD-\% with Tertiary Education, Women.

German men

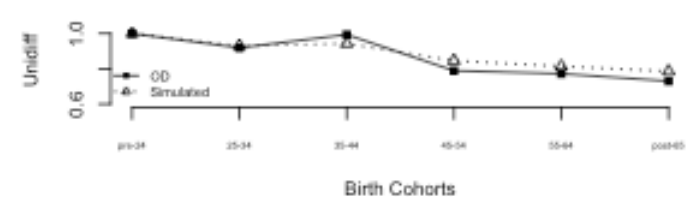

French men

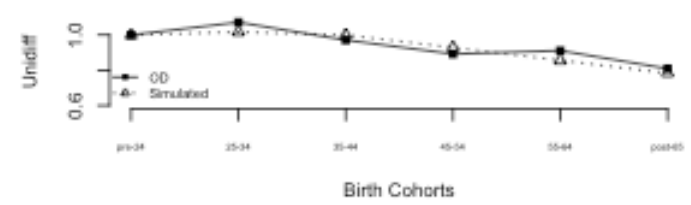

Swedish men

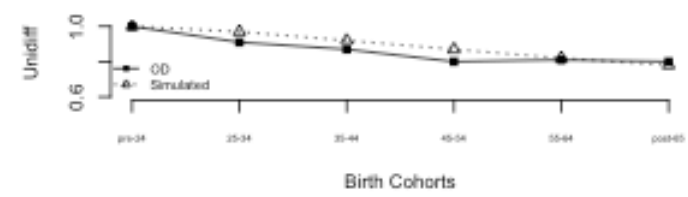

German women

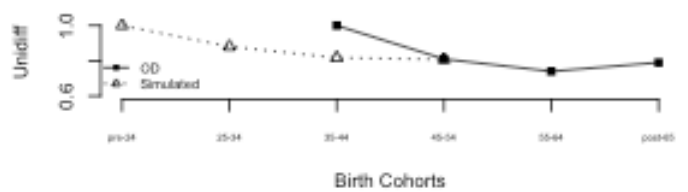

French women

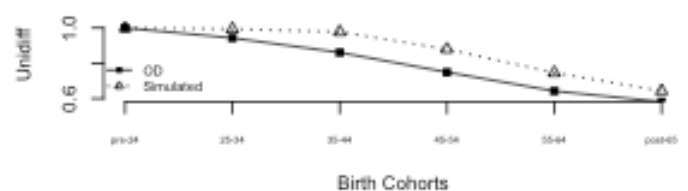

Swedish women

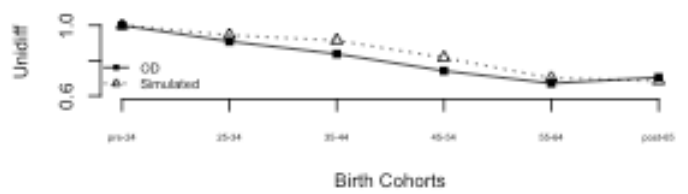

Figure 12a: OD Unidiff, actual and simulated, Germany, France, Sweden 

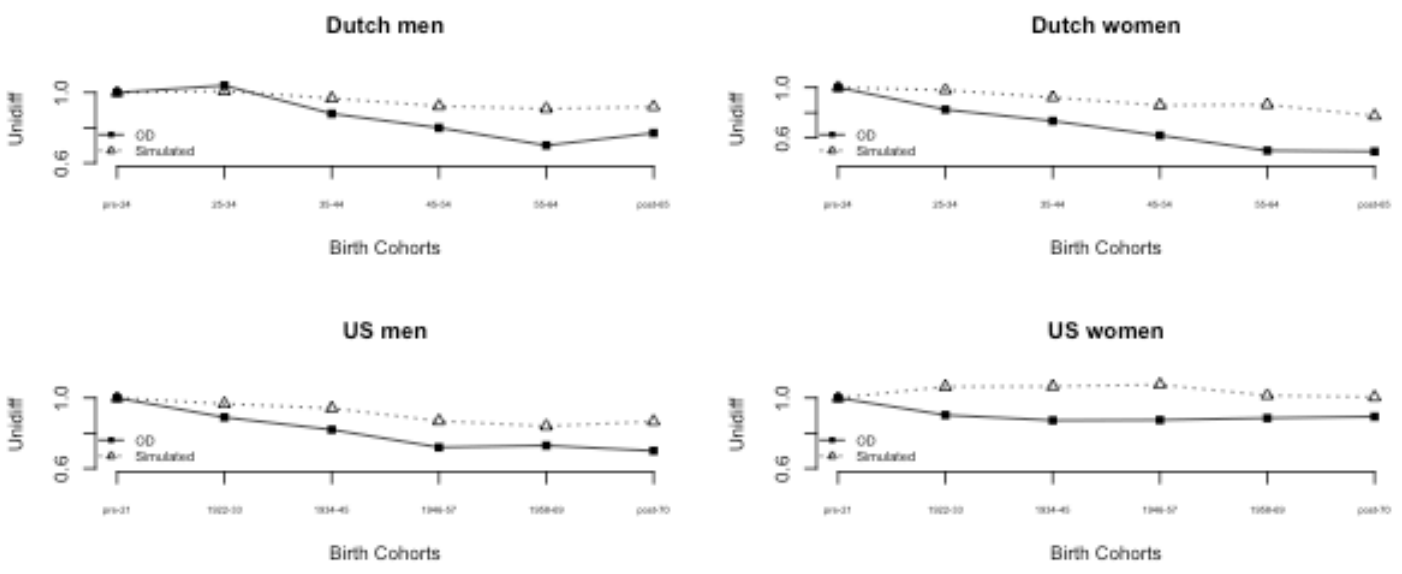

Figure 12b: OD Unidiff, actual and simulated, Netherlands and USA 